\title{
Eco-evolutionary dynamics in Pacific salmon
}

\author{
SM Carlson ${ }^{1}$, TP Quinn ${ }^{2}$ and AP Hendry ${ }^{3}$ \\ ${ }^{1}$ Department of Environmental Science, Policy, and Management, University of California, Berkeley, CA, USA; ${ }^{2}$ School of Aquatic and \\ Fishery Sciences, University of Washington, Seattle, WA, USA and ${ }^{3}$ Redpath Museum and Department of Biology, McGill University, \\ Montreal, Quebec, Canada
}

Increasing acceptance of the idea that evolution can proceed rapidly has generated considerable interest in understanding the consequences of ongoing evolutionary change for populations, communities and ecosystems. The nascent field of 'eco-evolutionary dynamics' considers these interactions, including reciprocal feedbacks between evolution and ecology. Empirical support for eco-evolutionary dynamics has emerged from several model systems, and we here present some possibilities for diverse and strong effects in Pacific salmon (Oncorhynchus spp.). We specifically focus on the consequences that natural selection on body size can have for salmon population dynamics, community (bearsalmon) interactions and ecosystem process (fluxes of salmon biomass between habitats). For example, we find that shifts in body size because of selection can alter fluxes across habitats by up to $11 \%$ compared with ecological (that is, numerical) effects. More generally, we show that selection within a generation can have large effects on ecological dynamics and so should be included within a complete ecoevolutionary framework.

Heredity (2011) 106, 438-447; doi:10.1038/hdy.2010.163; published online 12 January 2011

Keywords: eco-evolutionary feedbacks; evolutionary changes; natural selection; population ecology; community ecology; ecosystem ecology

\section{Introduction}

Biologists have long-recognized that ecology sets the stage for natural selection and adaptive evolution but have only recently started to fully appreciate the inverse: how ongoing evolutionary change influences ecology. Lag in acceptance of the latter causation was due, in part, to the long-held view that evolution and ecology occur on different time scales (Slobodkin, 1961); specifically, that evolution proceeds much slower than ecology. In recent decades, this view has changed with the accumulation of many examples of 'contemporary evolution', that is, evolution observed over dozens to hundreds of generations (for example, see reviews in Hendry and Kinnison, 1999; Kinnison and Hendry, 2001; Reznick and Ghalambor, 2001). With this growing appreciation for the rapidity of evolution, researchers are now considering its consequences for the dynamics of populations (for example, Hairston Jr et al., 2005; Kinnison and Hairston, 2007; Kinnison et al., 2008; Ezard et al., 2009), communities (for example, Fussman et al., 2007; Post et al., 2008) and ecosystems (for example, Harmon et al., 2009; Palkovacs et al., 2009), as well as the reciprocal feedbacks between evolution and ecology (Post and Palkovacs, 2009). The growing field of 'eco-evolutionary dynamics' considers these interactions.

Correspondence: Dr SM Carlson, Department of Environmental Science, Policy, and Management, University of California, 137 Mulford Hall \#3114, Berkeley, CA 94720, USA.

E-mail: smcarlson@berkeley.edu

Received 18 June 2010; revised 2 October 2010; accepted 15 November 2010; published online 12 January 2011
Eco-evolutionary dynamics (Figure 1) can be conceptualized across the three traditional levels of ecological organization: populations (for example, population size), communities (for example, species diversity) and ecosystems (for example, primary productivity). It is well established in the ecological literature that changes occurring at each of these levels can influence each of the other levels. Evolution influences these processes through interactions between these ecological processes and organismal phenotypes. For the eco-to-evo pathway, phenotypes can be shaped by selection deriving from population dynamics (for example, density dependence), community interactions (for example, predator-prey interactions) and ecosystem function (for example, nutrient levels). For the evo-to-eco pathway, the phenotypic changes can then influence population dynamics, community interactions or ecosystem function. This second set of causal effects is less well known and so it is the focus of this paper.

Most previous studies of eco-evolutionary dynamics have emphasized the role of phenotypic change thought to be due solely to evolution: that is, genetically based between-generation changes. However, phenotypic changes that influence ecological processes also could be the result of other processes. For instance, ecological variables can have plastic effects on organismal phenotypes (West-Eberhard, 2003), which could then influence ecological processes. Additionally, selection within a generation (before any resulting evolutionary change between generations) can shift phenotypes and thereby influence ecological processes. Phenotypic shifts within a generation because of either plasticity or selection, although not themselves representing evolution per se, 
nonetheless belong in a complete eco-evolutionary framework. We have chosen to focus on the effects of selection within a generation because this process has rarely been mentioned in the context of eco-evolutionary dynamics (but see Weese et al., 2011). As selection within a generation can lead to evolutionary change, we also extend our discussion and analyses of how local adaptation might influence eco-evolutionary dynamics.

We illustrate these ideas using Pacific salmon as an example. We first highlight several aspects of salmon biology that make them an excellent system for studying eco-evolutionary dynamics. We then apply the above ideas to salmon eco-evolutionary dynamics across populations, communities and ecosystems.

\section{Pacific salmon as a model system}

The life history of Pacific salmon, Oncorhynchus spp., has a number of implications for eco-evolutionary dynamics. First, like all salmonine fishes, Pacific salmon are philopatric, meaning that they return to their natal sites to breed (Dittman and Quinn, 1996; Hendry et al., 2004b). This natal homing behavior results in discrete breeding populations that can be subject to divergent local selection pressures (for example, Quinn et al., 2001a;

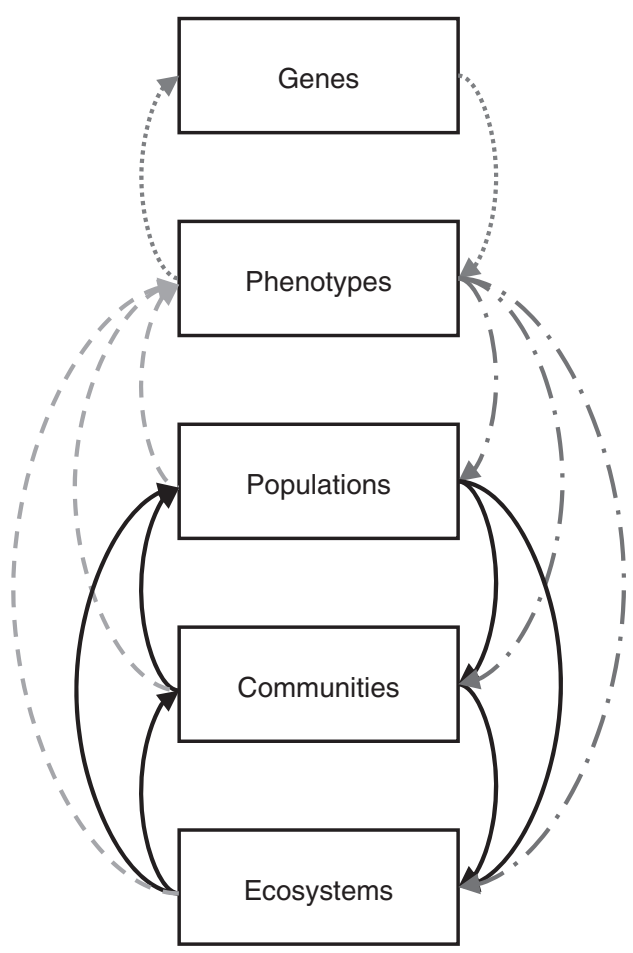

Figure 1 Conceptual model for understanding eco-evolutionary dynamics - a similar version appears in Bailey et al. 2009. The field of ecology has traditionally focused on the dynamics of populations, communities and ecosystems as well as feedbacks across these levels: that is, black solid lines in the figure. The field of evolutionary biology has traditionally focused on changes at the genetic or phenotypic levels, as well as feedbacks between them: that is, blue dotted lines in the figure. The field of eco-evolutionary dynamics considers both how changes in population, community and ecosystem dynamics affect phenotyes (green dashed lines) but also how phenotypic change influences populations, communities, and ecosystems (red dash-dotted lines). A full color version of this figure is available at the Heredity journal online.
Hamon and Foote, 2005; Carlson and Quinn, 2007; Carlson et al., 2009). Many fitness-related traits are heritable in this group (reviewed by Carlson and Seamons, 2008), and so spatially varying selection can drive adaptive divergence among populations. As a result, salmon populations often differ in many phenotypic traits (for example, Taylor, 1991; Fraser et al., 2011), including age-at-maturity and aspects of their body size and shape (for example, Quinn et al., 2001b).

Second, Pacific salmon are anadromous, meaning that they undertake migrations between freshwater breeding grounds and marine feeding grounds (Groot and Margolis, 1991; Hendry et al., 2004a; Quinn, 2005). This aspect of their life history allows Pacific salmon to take advantage of rich ocean feeding grounds while still breeding in ancestral freshwater environments. Depending on the population and species, anadromous individuals spend 1-7 years feeding and growing in the ocean where they achieve $\sim 99 \%$ of their total lifetime biomass (for example, Gende et al., 2002; Quinn, 2005). Moreover, survival is high and so they often breed at very high densities (in some cases, even after commercial fishing, over one adult salmon, each weighing $2-3 \mathrm{~kg} \mathrm{~m}^{-2}$; for example, Quinn et al., 2003). Consequently, even if their per capita ecological effects are small, their total effect could be large because they are so abundant.

Third, Pacific salmon are semelparous, dying at the end of their first and only breeding season. Consequently, Pacific salmon transport energy and nutrients in their bodies from the ocean into the freshwater ecosystems where they are then deposited. Spawning and dead salmon are consumed by numerous predators and scavengers, dispersing salmon tissue beyond their spawning habitats. The importance of these salmon inputs for aquatic and terrestrial ecosystems has been documented in detail (see reviews in Willson and Halupka, 1995; Cederholm et al., 1999; Gende et al., 2002; Schindler et al., 2003; Janetski et al., 2009). In addition to the importance of salmon as a resource subsidy, they are also ecosystem engineers because of the disturbance caused by their nest digging activities (for example, Field-Dodgson, 1987; Peterson and Foote, 2000; Moore et al., 2004). The ecological importance of salmon suggests that this is a system where eco-evolutionary dynamics will be manifest (see also Kinnison and Hairston, 2007; Kinnison et al., 2008; Waples et al., 2010).

\section{Eco-evolutionary dynamics of Pacific salmon}

Our consideration of eco-evolutionary dynamics will rely on data from a long-term research program in southwestern Alaska, USA. Hansen Creek is a small, springfed stream in the Wood River Lakes system that flows $2 \mathrm{~km}$ from a beaver pond at its head to Lake Aleknagik at its terminus. The creek supports a sizeable run of sockeye salmon (Oncorhynchus nerka), with the annual adult return from 1999 to 2009 ranging between 1976 and 20440 fishes (Figure 2). During July, salmon arrive at the creek mouth and stay there for days to weeks while they complete their maturation. Once mature, they enter the creek where all spawning activity takes place from late July through August. During this period, the creek is very shallow (averaging $10 \mathrm{~cm}$ deep) and flows are steady, facilitating daily surveys. These surveys typically consist of enumerating all live and dead fish, and noting 
their sex, location and mode of death (for example, 'stranded' at the shallow creek mouth, killed by bears in the creek or died of senescence in the creek). For a subset of these fish, body length (mid-eye to hypural plate) was measured and otoliths (ear stones) were removed for age determination. In the following sections, we use these data to describe how selection within a generation contributes to trait change. We then consider the consequences of this selection for several aspects of

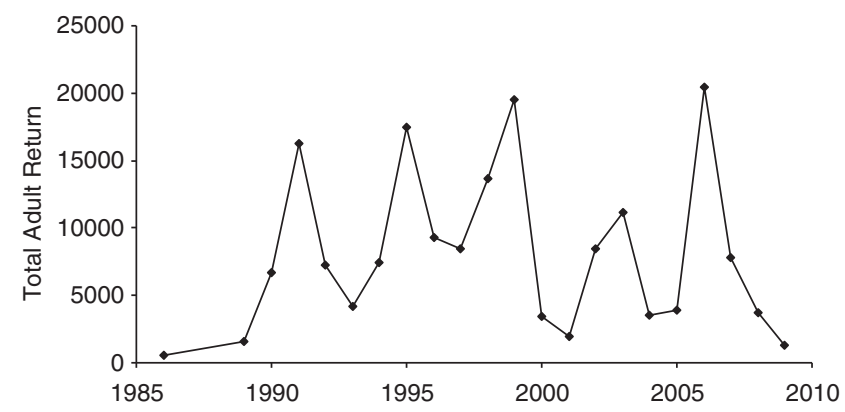

Figure 2 Total number of sockeye salmon spawning in Hansen Creek (1986-2009). population, community and ecosystem dynamics. Finally, we consider how divergent selection between Hansen and other nearby creeks shapes local adaptation and therefore can have ecological effects.

We focus on two sequential episodes of natural selection acting on body size. This trait was chosen because it is easily quantified and is a regular target of natural and sexual selection (for example, Fleming and Gross, 1994; Quinn et al., 2001a; Hamon and Foote, 2005; Seamons et al., 2007), as well as human-induced (fishery) selection (for example, Kendall et al., 2009; Kendall and Quinn, 2009). In addition, body size is expected to influence nutrient subsidy and ecosystem engineering effects.

Adult salmon returning to breed in Hansen Creek face a first episode of selection as they negotiate the creek's shallow mouth on their way into the creek proper (Quinn and Buck, 2001; Carlson and Quinn, 2007) (Figure 3). The water at the creek mouth is exceedingly shallow $(\mathrm{ca} 4 \mathrm{~cm}$ at the deepest part) and larger individuals often cannot remain upright, falling over onto their sides and dying ('stranding'). The difficulty in passing the creek's mouth, and therefore the intensity of selection, is largely a function of water level in the lake, which varies among
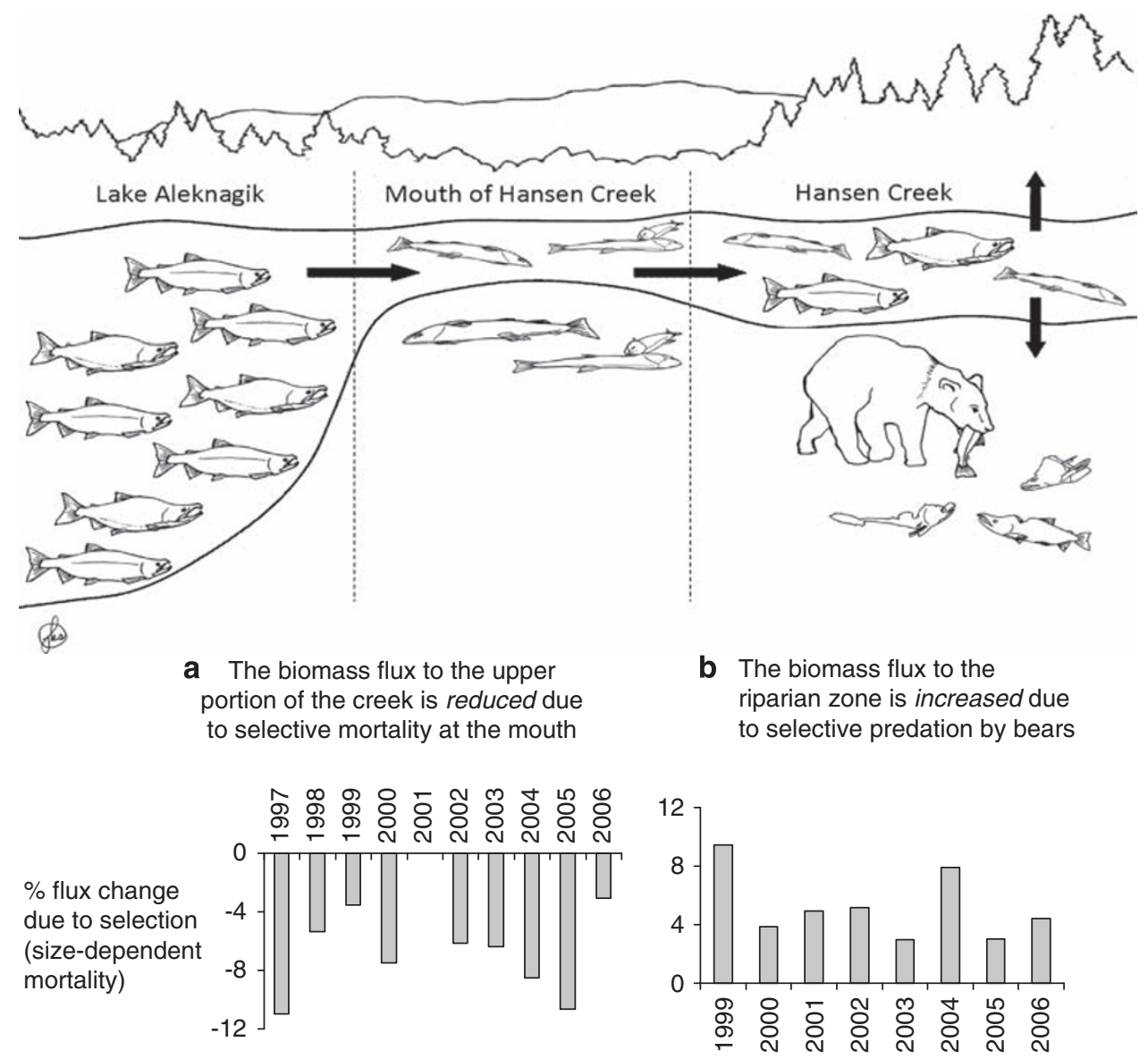

Figure 3 Conceptual illustration of the Hansen creek study system highlighting downstream Lake Aleknagik, the shallow creek mouth, the upper portion of the creek and the creek riparian zone. Fluxes were calculated across habitats, with the flux change into the upper reaches of the creek reduced by mortality at the creek mouth and the flux change into the riparian zone increased by the transportation of salmon carcasses from the creek to the riparian zone by bears. We estimated the relative influence of ecology (size-independent mortality) and selection (size-dependent mortality) on these flux changes across years, and have included two plots to illustrate the influence of selection on the flux change into the creek because of mortality at the creek mouth (a) and the flux change into the riparian zone because of predation by bears (b). Artwork by J Kiyoko Shiosaki. 


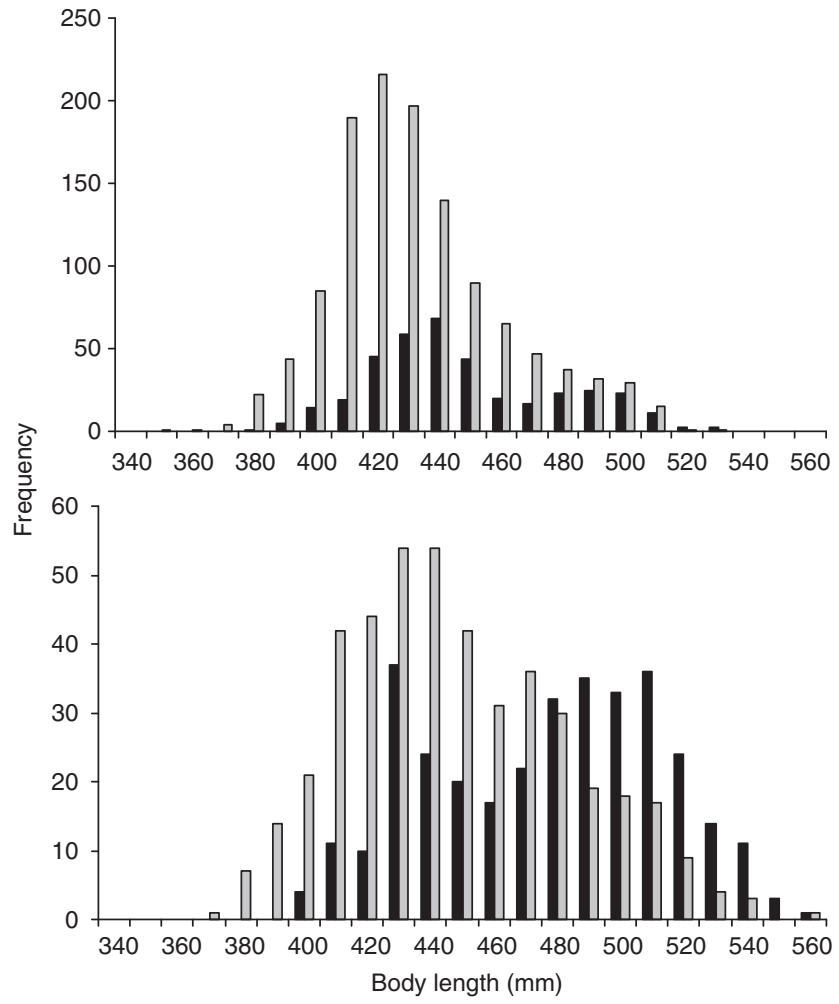

Figure 4 Length-frequency histograms highlighting the size selection occurring at the mouth of Hansen Creek for both female (top) and male (bottom) sockeye salmon in 2004, a year of strong selection at the creek mouth (Carlson and Quinn, 2007). The two bars represent those fish that stranded and died at the mouth of creek (black bars) versus those that successfully ascended the creek mouth and died in the creek itself (gray bars). Note that only a subset of fish dying at the mouth versus instream were measured for length and so these data emphasize size selection only, and not the overall mortality that occurred at the mouth.

years owing to temperature and precipitation. Years of low water are associated with major stranding events at the creek mouth; up to $42 \%$ of the returning males and $26 \%$ of the females in a given year have died in this manner. This mortality is highly size-biased, consistently acting against the largest bodied individuals (Carlson and Quinn, 2007), with Figure 4 showing an example.

The salmon that successfully ascend the mouth of Hansen Creek then face a second episode of selection because of predation by bears (Ruggerone et al., 2000; Quinn and Buck, 2001; Quinn et al., 2001a; Carlson et al., 2009) (Figure 3). This mortality is also highly sizeselective, as bears tend to kill relatively large fish, with Figure 5 showing an example. Among year variation in the intensity of selective predation likely varies in relation to the number of bears and the total number of salmon returning to Hansen Creek. That is, bears are expected to be highly selective when the number of salmon available to them is large (for example, 2006, Figure 2) and the opportunity to be selective is therefore high.

\section{Population dynamics}

Selection influences mortality or reproductive success and can therefore influence population dynamics (for example, Saccheri and Hanski, 2006; Kinnison et al., 2008; Williams et al., 2008; Ezard et al., 2009; Pelletier et al.,

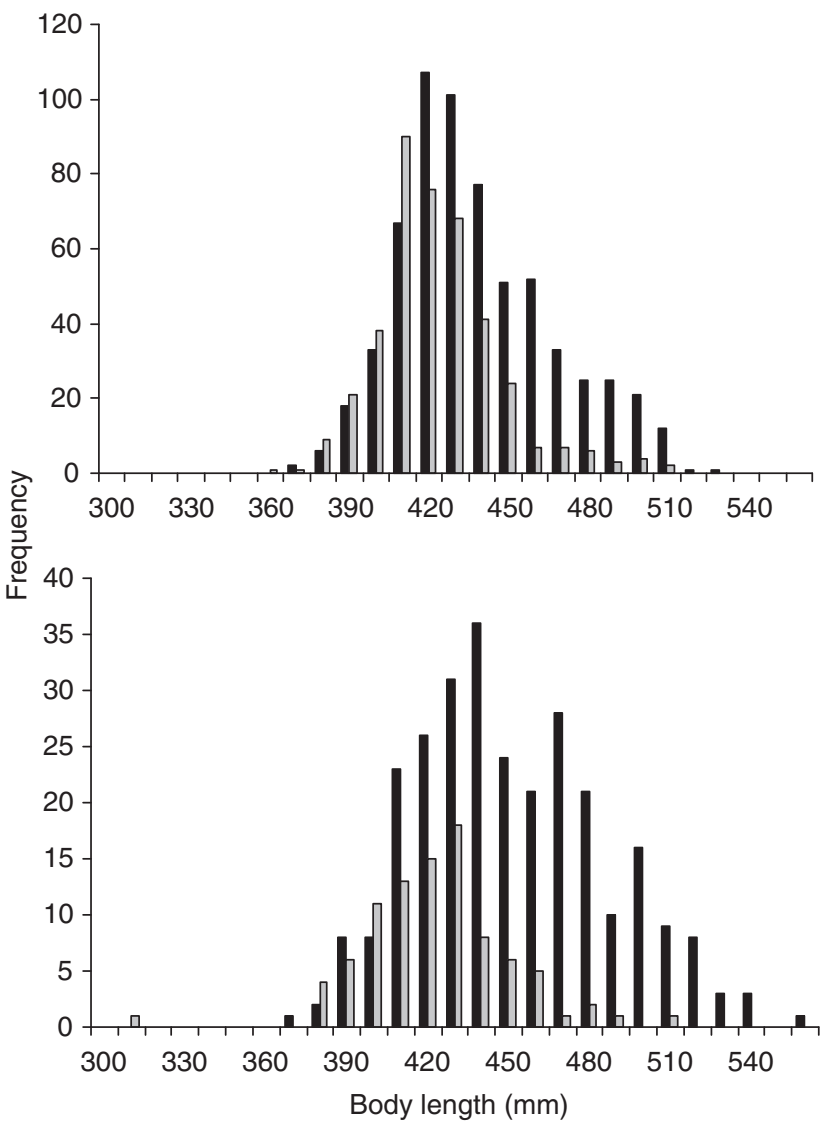

Figure 5 Length-frequency histograms for a single year (2004) highlighting size-selective predation by bears on Hansen Creek sockeye salmon plotted separately for females (top) and males (bottom). The two bars represent those fish that died of senescence (gray bars) versus those that were killed by bears (black bars). Note that only a subset of fish dying of senescence versus because of bears were measured for length and so these data emphasize size-selective predation only, and not the overall mortality because of bear predation.

2009). Here, we consider how the aforementioned two episodes of selection on body size might influence salmon fecundity and age structure, which should then have consequences for their population dynamics.

By changing the body size distribution of salmon spawning in the creek, selection at the creek mouth and by bears has the potential to drive correlated selection on the number of eggs per female. As smaller fish are less fecund and have smaller eggs than do larger fish (Beacham and Murray, 1993), a shift toward smaller fish may result in fewer recruits per spawner relative to years dominated by larger fish (see also Hutchings, 2005). Thus, selection on body size can drive correlated selection on traits that influence population dynamicsalthough this has not yet been formally investigated.

In addition, because body size is strongly influenced by the number of years spent in the ocean, selection acting on body size has the potential to drive correlated selection on salmon age-at-maturity (Quinn and Buck, 2001). The majority of sockeye salmon returning to Hansen Creek have spent a single year in fresh water and 2 years at sea, but some individuals have also spent 1 or 3 years at sea (Table 1). These different ocean ages strongly correlate with body size; those spending more 
Table 1 Relationship between the number of years spent by Hansen Creek sockeye salmon in freshwater and the number of years they spent at sea, expressed as a percentage of the total sample

\begin{tabular}{lcccccccc}
\hline Years in freshwater & \multicolumn{7}{c}{ Years spent at sea } \\
\cline { 2 - 8 } & 1 Male & 1 Female & 2 Males & 2 Females & 3 Males & 3 Females & Sample males & Sample females \\
\hline 1 & 0.01 & 0.00 & 0.61 & 0.64 & 0.28 & 0.27 & 0.90 \\
2 & 0.00 & 0.00 & 0.08 & 0.08 & 0.02 & 0.02 & 0.10 & 0.91 \\
Sample & 0.02 & 0.00 & 0.69 & 0.72 & 0.30 & 0.28 & 1.00 & 1.00
\end{tabular}

Otolith samples for age determination were collected from approximately 100 males and 100 females salmon each year from 1947 to 2005.

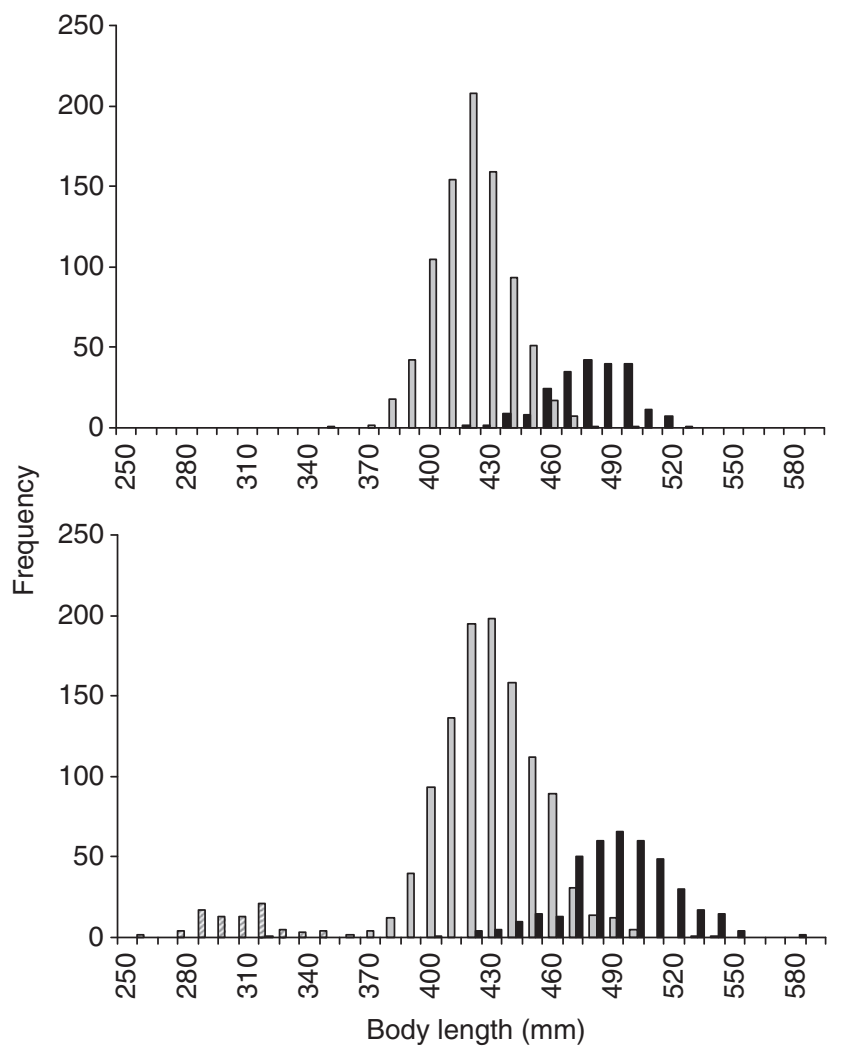

Figure 6 Length-at-ocean age for Hansen Creek female (top) and male (bottom) sockeye salmon based on data collected across the years 1998-2005. The bars correspond to ocean age 1 (black diagonal lines, males only), 2 (gray bars) and 3 (black bars).

time in the ocean are larger (Figure 6). Figure 7 shows an example of the correlated selection on age at maturity from a year of particularly strong direct selection on body size at the creek mouth. In particular, a comparison of the estimated pre-selection ages of fish returning to the mouth of Hansen Creek (Figure 7b) with the postselection ages of fish that successful ascending the creek mouth to enter the creek proper (Figure 7c) shows a pronounced shift toward younger (two-ocean as opposed to three-ocean) fish.

An important effect of age structure on population dynamics is the degree to which generations are overlapping. When individuals from a given birth-year cohort mostly return to breed at the same age, little overlap occurs between different cohorts, which can lead to a pronounced cohort effect across years (for example, large and small population sizes occurring in different years at a regular frequency). Such periodical systems can be quite vulnerable to disturbances in a single year that can eliminate one of the cohorts with little hope of recovery through recruitment from the local population (although recruitment can occur from other populations). In contrast, when individuals from the same birth-year cohort return to breed at multiple ages, cohort effects are less dramatic and the system can be more robust to episodic disturbances. In Hansen Creek, selection against larger fish leads to correlated selection against older fish (Figure 7), which simplifies the age-structure and increases the proportion of fish breeding as 4-year olds (as opposed to 5-year olds). The large proportion of 4-year olds breeding in this population has resulted in population cycles occurring every 4 years with, for example, large returns observed in years 1991, 1995, 1999 and 2003 (Figure 2). Thus, selection on body size in this population has likely indirectly influenced population dynamics.

\section{Community dynamics}

Some investigators (for example, Bailey et al., 2009) have argued that community (and ecosystem) variables are further removed from phenotypes than are population dynamics, and so the effects of phenotypes should become weaker from the population level to the community level to the ecosystem level. However, this might not be the case when traits can have direct as well as indirect effects on communities and ecosystems. By direct effects, we mean that the specific trait value of individuals is relevant to a particular community- or ecosystem-level process. For example, a salmon of one size will have a different effect on the community than will a salmon of a different size. By indirect effects, we mean that a direct effect at one ecological level can then influence other ecological levels. For example, large salmon will have more offspring than smaller ones and might therefore increase population size in the next generation, with this greater abundance having an effect on the ecosystem independent of the specific trait values of the individuals. The indirect effects are more obvious because it is easy to envision how trait change influences population size, which then influences ecological variables. Here, we will consider the less obvious possibility of direct effects of trait change because of selection on community interactions-namely predatorprey interactions.

What are the consequences of selection at the creek mouth for bear ecology? When salmon are sufficiently abundant and easy to catch, bears kill salmon selectively on the basis of size (for example, Quinn and Kinnison, 1999; Ruggerone et al., 2000; Quinn and Buck, 2001), sex (for example, Quinn and Kinnison, 1999; Ruggerone et al., 2000) or stage of senescence (for example, Gende 
a pre-selection
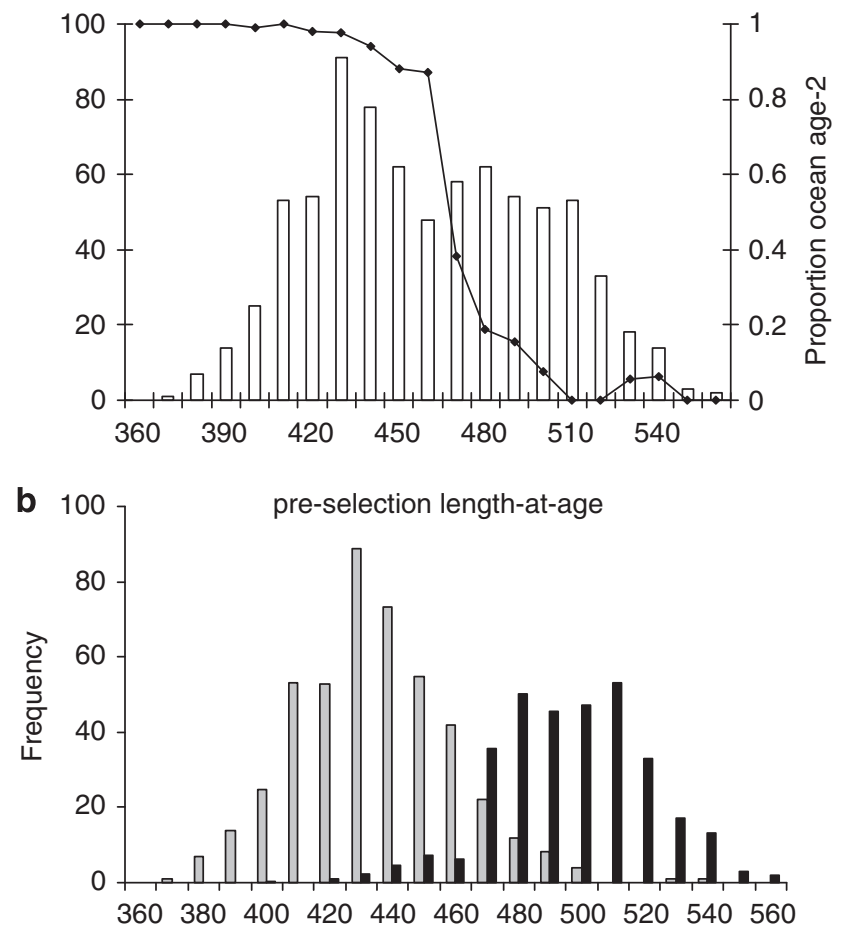

C

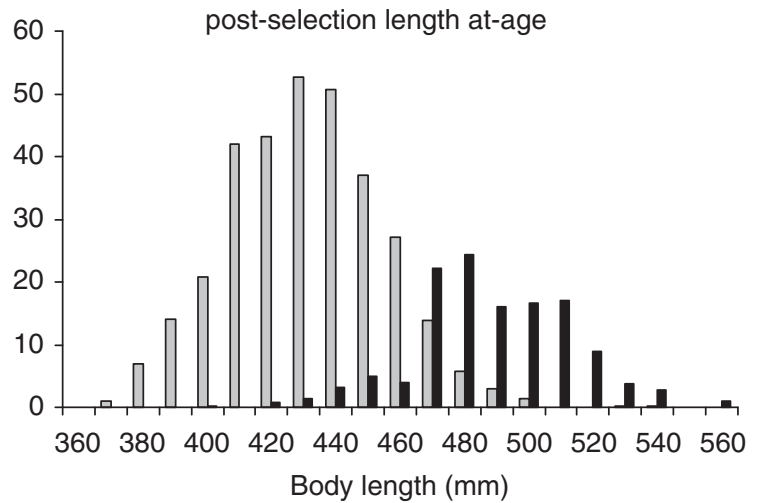

Figure 7 Selection on salmon body size leads to indirect selection on age composition, which has implications for population dynamics. In panel (a), we have plotted the length-frequency histogram (left $y$ axis) for the subset of male salmon that were measured for body length during the 2004 spawning season, representing males that died at the mouth or in the stream. The right $y$ axis shows the percentage of known-aged males in each length bin that spent 2 years at sea $(1$ minus this proportion represents the percentage of known-aged males that spent 3 years at sea). We then estimated the age of all fish measured for length based on the percentage of known-aged two-ocean and three-ocean fish in each length bin, which we have plotted in panel (b). Note that this represents the pre-selection distribution of length-at-age for the subset of fish measured for body length. Finally, we estimated the post-selection distribution of length-at-age by estimating the age of all fish that successfully ascended the creek mouth, which we have plotted in panel (c). A comparison of panels $\mathbf{b}$ and $\mathbf{c}$ reveals that selection against large-bodied salmon indirectly favors younger (two-ocean) fish

et al., 2004; Carlson et al., 2007). Selective predation is then followed by selective consumption: bears consume less salmon biomass per fish as salmon density increases (Gende et al., 2001); and they also target energy-rich (that is, newly arrived) fish (Gende et al., 2004), as well as energy-rich body parts such as the eggs of females (Gende et al., 2001). Body size selection based on stranding at the creek mouth could therefore have bioenergetic consequences for the bears, as the per-fish energetic reward is less for small fish than large fish. Although bears do scavenge some fish at the creek mouth, they more often use the upper portions of the creek, where they are able to avoid humans and can also spread out and minimize interactions with other bears. Thus, in years when this selection at the creek mouth is intense, it might increase the chances of energy limitation for bears. For example, bears might have to increase their foraging effort, change their selectivity for energy-rich fish (Gende et al., 2004) or change their selectivity for energy-rich tissues (Gende et al., 2001). These effects are unlikely, however, to be particularly important when the overall salmon population is large and bears can easily catch the fish.

Another potential community-level effect of selection on salmon body size is related to their nest digging activity. By disturbing the local substrate, salmon nest digging results in short-term decreases in insect biomass (for example, Field-Dodgson, 1987; Moore and Schindler, 2008). The predictable disturbance also influences insect life histories, where emergence is timed to occur before salmon arrival, presumably to avoid mortality because of salmon nest digging activities (Moore and Schindler, 2010). The size of the nest excavated by a salmon female is related to her body size; larger females dig larger nests (Steen and Quinn, 1999). By changing the distribution of female body size, selection from stranding and predation may thus influence insect community dynamics.

These two potential community-level effects of selection (bear energetics and aquatic invertebrate communities) have not been explicitly tested-but they seem reasonable possibilities. At the same time, the main effect of stranding may be numerical (reducing the number of salmon) rather than selective (reducing their size). If so, the effects of selection within a generation may be weak in relation to simple non-selective mortality. We will revisit this idea of the relative importance of selection in the next section when discussing fluxes of salmon biomass to the creek.

\section{Ecosystem dynamics}

The importance of salmon to ecosystem processes can be broadly categorized into trophic influences (subsidy, Polis et al., 1997) versus non-trophic influences (ecosystem engineering, Jones et al., 1994), both of which have been studied extensively from an ecological perspective (for a recent review, see Janetski et al., 2009). In the first case, salmon subsidies from the ocean are transferred into freshwater and terrestrial ecosystems through direct consumption by animals and through excretion, decomposition and sub-surface water movement (reviewed in Gende et al., 2002). The flux of salmon biomass from the ocean to freshwater can be substantial, and varies among years because of variation in salmon density and body size. In addition, whether salmon carcasses accumulate at the mouth of the creek, in the creek itself or in the riparian zone has consequences for consumers and nutrient dynamics. Here, we explore the potential consequences of trait change due selection on fluxes of 
salmon biomass from the creek mouth into the upper portions of the creek (influenced by selection at the creek mouth) and from the creek into the riparian zone (influenced by selection by bears in the creek) (Figure 3).

To infer the extent to which phenotypic change because of selection matters within the larger scheme of external driving factors, we partition the change in flux of salmon biomass into that because of selective mortality (hereafter 'flux change because of selection') versus non-selective mortality (hereafter 'flux change because of ecology'). This approach is in analogy to earlier work by Hairston et al. (2005) and Ezard et al. (2009) asking how much of the variance in population size of a target organism from one generation to the next is the result of phenotypic change between generations (there considered 'evolution') versus external environmental drivers (there considered 'ecology'). In our extension of this approach, we first estimated how the flux into the creek was influenced by the combined effects of 'ecology and selection' (measured selective and non-selective mortality at the creek mouth), and we then partitioned this combined effect into the fraction that might be considered purely ecological (influence of stranding on fish numbers) versus that because of selection (influence of stranding on average phenotype). This is a simplification, of course, because the influence of stranding of fish numbers will depend on overall body size, which is the product of past selection.

We first calculated the total biomass flux of salmon returning to Hansen Creek to breed as the total number of fish returning to the creek (before actually entering the creek) multiplied by the average mass of those fish. This was calculated separately for males and females and then summed: average flux across years 1997-2006 was $17281 \mathrm{~kg}$ (range $5066-35974 \mathrm{~kg}$ ). We then calculated the flux into the creek proper after the combined effects of size-independent mortality (ecology) and size-dependent mortality (selection) at the creek mouth as the number of fish that successfully ascended the mouth multiplied by their average mass. Owing to mortality at the creek mouth, the total flux of salmon biomass into Hansen Creek was reduced annually by ecology and selection combined by an average of $15 \%$ (range $<1-36 \%$ ), which corresponds to an average annual loss of $2913 \mathrm{~kg}$ of salmon biomass (range $49-8805 \mathrm{~kg}$ ). To estimate the flux change because of 'ecology' alone, we calculated the biomass removed at the mouth because of size-independent mortality. To do this, we multiplied the number of fish that died at the creek mouth by the average mass of the total return, thus simulating mortality without selection. The average flux change because of ecology alone across years 1997-2006 was thereby estimated as $2759 \mathrm{~kg}$ (range 51-8534 kg). To estimate the flux change because of selection alone, we calculated the biomass retained at the creek mouth because of size-dependent mortality. To do this, we multiplied the number of fish that died at the creek mouth by the difference in body mass between those that died and the total return (before entering the creek), thus simulating selection without mortality. The average flux change because of selection alone across years 1997-2006 was $154 \mathrm{~kg}$ (range <1$289 \mathrm{~kg}$ ). Thus, an average of $6 \%$ of the change in flux at the creek mouth was because of selection (range $0-11 \%$, interannual variation highlighted in Figure 3a). These calculations show that (1) ecology (influence of stranding on fish numbers) has a larger role than selection (influence of stranding on fish body size), but (2) that selection within a generation does also contribute. Whether this modest selection influences the system within a given generation is not yet known. However, as we will explain later, the evolutionary consequences of selection across multiple generations will likely have much larger effects.

As with the above procedure, we estimated how the flux into the riparian zone was influenced by the combined effects of 'ecology and selection' through the measured movement of fish biomass by bears. We partitioned this combined effect into that which might be considered purely ecological (influence of bears on the number of fish transported to the riparian zone) versus that because of selection (influence of bears on the average body size of transported fish). We first estimated the combined effect of ecology and selection as the number of fish transported into the riparian zone multiplied by the average mass of bear-killed fish. We needed to correct for the amount of tissue consumed by bears because it is the non-consumed part of the carcass that is left in the riparian zone. For this, we multiplied the above quantity by one minus the average proportion of tissue consumed by bears (field data yielded estimates of 24 and $22 \%$ consumption of female and male salmon carcasses, respectively, by bears, Quinn et al., 2009). This yielded an estimate of the average annual flux of salmon biomass into the riparian zone of $3300 \mathrm{~kg}$ (range $638-9121 \mathrm{~kg}$ ) across years 1999-2006 (see also Table 4 of Quinn et al., 2009). This estimate excludes salmon materials that were first ingested and later excreted by bears in the riparian zone, and so it represents a conservative estimate of the riparian flux because of bear predation. Next, we estimated the influence of ecology alone on the flux change as the number of fish transported multiplied by the average mass of fish in the stream (before removal by bears), again corrected for the average proportion of tissue left unconsumed by bears. The average flux change because of ecology thus calculated was $3102 \mathrm{~kg}$ (range $588-8259 \mathrm{~kg}$ ). Finally, we estimated the influence of selection alone on the flux change as the number of fish transported multiplied by the difference in the average mass between fish in the stream (before removal by bears) and the bear-killed fish, again corrected for the average proportion of tissue left unconsumed by bears. This calculation yielded an estimate of the average flux change because of selection alone of $198 \mathrm{~kg}$ (range $37-862 \mathrm{~kg}$ ). Thus, the flux change to the riparian zone was increased, on average, by 5\% (range 3-9\%) because of the selection of larger fish by bears (interannual variation highlighted in Figure 3b).

In addition to the above consumptive effects, the nest digging activity of salmon can have profound impacts on their spawning habitats, as introduced above. In particular, their nest digging activity disturbs the local substrate, resulting in short-term decreases in algal biomass (for example, Moore and Schindler, 2008), large seasonal pulses of sediments, nitrogen, and phosphorous to downstream areas (Moore et al., 2007), changes in stream ecosystem metabolism (Holtgrieve and Schindler, In Press) and changes in surface particle distribution, with consequences for scour depth (Montgomery et al., 1996). As nest size and therefore disturbance is related to 
female body size, selection on body size has the potential to influence the impact of salmon as ecosystem engineers in streams and their selective effect on insect life histories.

The above estimation did not include all potential selective effects. For instance, the population is subject to another major source of predation-a commercial fishery-before they reach the breeding grounds, which has a strong numerical effect (removing upward of $50 \%$ of the salmon in many years). This fishery is also highly size-selective in removing larger fish and so might well have similar or larger impacts on eco-evolutionary dynamics (Kendall and Quinn, 2009; Kendall et al., 2009). Overall, then, the combined effects of selection across the entire adult phase may have large cumulative effects on ecosystem processes.

\section{Importance of eco-evolutionary dynamics to local adaptation}

We have so far emphasized how ecological processes can be influenced by phenotypic changes within a generation because of selection. We now extend this consideration to how selection within a generation drives phenotypic change across generations, which then has influences on ecological processes.

Traits under selection are expected to evolve if they have a genetic basis. In a review of trait heritabilities and genetic correlations for salmonine fishes, Carlson and Seamons (2008) reported that the median heritabilities $\left(h^{2}\right)$ across studies for length-at-maturity and age-atmaturity were 0.29 and 0.21 , respectively, which suggests substantial evolutionary potential. Moreover, genetic correlations between length-at-age and life history traits were strong and positive: median correlation across studies $=0.34$ (Carlson and Seamons, 2008), suggesting that selection on size could drive correlated evolution of age-at-maturity, as well as other traits (see also Kinnison et al., 2011).

As introduced earlier, bears generally select large individuals (Quinn and Kinnison, 1999; Ruggerone et al., 2000; Quinn and Buck, 2001) in streams where the catching of salmon is easy (for example, small and structurally simple streams), whereas they feed less selectively in streams where the catching of salmon is difficult (for example, large rivers; Gende et al., 2004; Carlson et al., 2007). Hansen Creek falls at former end of this continuum. It is relatively small $(10 \mathrm{~cm}$ deep, $3-4 \mathrm{~m}$ wide) and structurally simple, and the bears are highly size selective (for example, Quinn and Buck, 2001; Quinn et al., 2001a). Exacerbating this selection is the stranding at the creek mouth, which is not as common in nearby streams (Quinn and Buck, 2001; Carlson and Quinn, 2007). As these two selective forces are stronger in Hansen Creek than in most other nearby sockeye salmon populations (Carlson et al., 2009), we would expect evolutionary differences in body size among populations, and this is indeed the case. As expected, Hansen Creek salmon are smaller than those in most other creeks-even after accounting for the immediate effects of selection within a generation (Quinn et al., 2001b).

Thus, local selective effects that differ between creeks have influenced adaptive divergence in body size among salmon populations, which should influence
Eco-evolutionary salmon dynamics

SM Carlson et al

creek-specific population, community and ecosystem dynamics. That is, each of the above effects discussed for selection within a generation at Hansen Creek should play out in an evolutionary sense between Hansen Creek and other salmon populations in the vicinity. We exemplify these potential effects by extending our previous consideration of nutrient fluxes to an amongpopulation context. That is, we assume that the body size differences among the streams are the product of evolutionary divergence (Quinn et al., 2001b; Carlson et al., 2009) and evaluate the ecological consequences by asking what would happen if Hansen Creek was populated by fish with body sizes typical of the other streams. Specifically, we re-calculated the Hansen total flux based on males using the average body size of male salmon from two neighboring populations, Bear and Yako creeks. These results show that the total flux into Hansen Creek would be much higher (30-32\%) if not for adaptation to local conditions that has lead to the evolution of small size.

In short, evolution of body size and correlated traits among salmon populations has certainly influenced local ecological dynamics. We have only isolated one such effect by hypothetically varying body length independent of other traits (for example, weight at length, which also varies among populations). Thus, our calculations did not include all ecological or evolutionary effects that might influences fluxes of salmon biomass across habitats. For example, populations might be more abundant when fish are smaller/younger. Consequently, the evolutionary effect that we just described (smaller salmon) could be offset by opposing ecological effects (more salmon). Similarly, evolutionary forces other than selection might limit the influence of body size divergence among populations. For example, while selection should facilitate the adaptive divergence of proximate populations, gene flow among them should constrain their divergence (Hendry et al., 2001), and so the potential for among-population divergence in eco-evolutionary dynamics might be larger when gene flow is less.

How quickly might eco-evolutionary differences arise owing to local adaptation? In our post-glacial study system, the tension between selection facilitating and gene flow constraining divergence has played out over thousands of years but the observed differences probably arose much more quickly. For instance, in introduced populations, body size can evolve by $10 \%$ or more in only dozens of generations in response to local selection pressures (for example, Kinnison et al., 1998; Hendry et al., 2000). Thus, evolutionary change is likely to influence eco-evolutionary dynamics on contemporary time scales.

We next consider the special case where eco-evolutionary dynamics could represent true feedbacks, that is, a phenotypic trait is influenced by the same ecological variable that the same phenotypic trait then influences (Post and Palkovacs, 2009). For instance, feedbacks seem possible with respect to bear predation. That is, selection on salmon body size that drives the evolution of smaller salmon body size should influence bear ecology, which could then influence the intensity of size-biased predation, and so on. In contrast, feedbacks seem unlikely with respect to selection owing to stranding at the creek mouth. That is, selection at the creek mouth influences the evolution of salmon phenotypes across generations, 
but those phenotypes do not then influence the ultimate factor that causes stranding in the first place: water level at the creek mouth. (However, evolution across generations should influence average body sizes, which should then influence the number of fish stranding at a given body size.) When true eco-evolutionary feedbacks are present, this might accelerate divergence among populations if selection drives adaptations to local ecological conditions, leading to evolutionary change in traits that affect local ecology, thereby resulting in a change in the selective pressure itself. This and many of the other ideas we presented have yet to be demonstrated experimentally, suggesting many avenues for future research.

\section{Summary}

We first proposed and then quantified some likely influences of selection within a generation on ecological processes in and around salmon spawning streams. When these effects could be quantified, they were not large (average about 5-6\%, maximum 9-11\%) in relation to basic non-selective effects of mortality. However, the total evolutionary effects will certainly be much largerwe only considered one trait (body length) and we did not consider all episodes of selection acting on the fish. In addition, the cumulative effects of selection across generations lead to adaptive divergence among populations that clearly has much larger ecological consequences. Our attempt to estimate one such consequence involved the direct effects of change in fish phenotypes on nutrient flux. However, evolution is also expected to influence population dynamics, and so many of the ecological (numerical) effects we describe will also be at least partly the indirect effects of evolution. In short, our demonstration is merely a heuristic one of the potential for evolutionary processes to influence ecological dynamics. Future work may show that the sum total of all such effects is dramatic, at least in some cases, and should therefore be considered in studies of how salmon influence their environment.

\section{Conflict of interest}

The authors declare no conflict of interest.

\section{Acknowledgements}

We thank Craig Primmer for the invitation to contribute a paper to this special issue on the topic of 'genetics of local adaptation in salmonid fishes'. TPQ's long-term work on Hansen Creek sockeye salmon has been funded from many sources including the commercial salmon processing industry, the National Science Foundation, the Gordon and Betty Moore Foundation and the University of Washington's School of Aquatic and Fishery Sciences. SMC was supported by the National Science Foundation (DEB-0915173) while writing this paper. Jonathan Moore and TPQ contributed photographs to help guide the artwork.

\section{References}

Bailey JK, Schweitzer JA, Ubeda F, Koricheva J, LeRoy CJ, Madritch MD et al. (2009). From genes to ecosystems: a synthesis of the effects of plant genetic factors across levels of organization. Philos T Roy Soc B 364: 1607-1616.

Beacham TD, Murray CB (1993). Fecundity and egg size variation in North American Pacific salmon (Oncorhynchus). J Fish Biol 42: 485-508.

Carlson SM, Hilborn R, Hendry AP, Quinn TP (2007). Predation by bears drives senescence in natural populations of salmon. PLOS ONE 2: e1286.

Carlson SM, Quinn TP (2007). Ten years of varying lake level and selection on size-at-maturity in sockeye salmon. Ecology 88: $2620-2629$.

Carlson SM, Rich HB, Quinn TP (2009). Does variation in selection imposed by bears drive divergence among populations in the size and shape of sockeye salmon? Evolution 63: 1244-1261.

Carlson SM, Seamons TR (2008). A review of quantitative genetic components of fitness in salmonids: implications for adaptation to future change. Evol Appl 1: 222-238.

Cederholm CJ, Kunze MD, Murota T, Sibatani A (1999). Pacific salmon carcasses: essential contributions of nutrients and energy for aquatic and terrestrial ecosystems. Fisheries 24: 6-15.

Dittman AH, Quinn TP (1996). Homing in Pacific salmon: mechanisms and ecological basis. J Exp Biol 199: 83-91.

Ezard THG, Côté SD, Pelletier F (2009). Eco-evolutionary dynamics: disentangling phenotypic, environmental and population fluctuations. Philos T Roy Soc B 364: 1491-1498.

Field-Dodgson MS (1987). The effect of salmon redd excavation on stream substrate and benthic community of two salmon spawning streams in Canterbury, New Zealand. Hydrobiologia 154: 3-11.

Fleming IA, Gross MR (1994). Breeding competition in a Pacific salmon (coho, Oncorhynchus kisutch)-measures of natural and sexual selection. Evolution 48: 637-657.

Fraser DJ, Weir LK, Bernatchez L, Hansen MM, Taylor EB (2011). Extent and scale of local adaptation in salmonid fishes: review and meta-analysis. Heredity 106: 404-420.

Fussman GF, Loreau M, Abrams PA (2007). Eco-evolutionary dynamics of communities and ecosystems. Func Ecol 21: 465-477.

Gende SM, Edwards RT, Willson MF, Wipfli MS (2002). Pacific salmon in aquatic and terrestrial ecosystems. Bioscience 52: 917-928.

Gende SM, Quinn TP, Hilborn R, Hendry AP, Dickerson B (2004). Brown bears selectively kill salmon with higher energy content but only in habitats that facilitate choice. Oikos 104: 518-528.

Gende SM, Quinn TP, Willson MF (2001). Consumption choice by bears feeding on salmon. Oecologia 127: 372-382.

Groot C, Margolis L (eds) (1991). Pacific Salmon Life Histories. University of British Columbia: Vancouver.

Hairston Jr NG, Ellner SP, Geber MA, Yoshida T, Fox JA (2005). Rapid evolution and the convergence of ecological and evolutionary time. Ecol Lett 8: 1114-1127.

Hamon TR, Foote CJ (2005). Concurrent natural and sexual selection in wild male sockeye salmon, Oncorhynchus nerka. Evolution 59: 1104-1118.

Harmon LJ, Matthews B, DesRoches S, Chase J, Shurin J, Schluter D (2009). Evolutionary diversification in stickleback affects ecosystem functioning. Nature 458: 1167-1170.

Hendry AP, Bohlin T, Jonsson B, Berg OK (2004a). To sea or not to sea? Anadromy versus residency in salmonids. In: Hendry AP, Stearns SC (eds). Evolution Illuminated: Salmon and Their Relatives. Oxford University Press: Oxford, pp 92-125.

Hendry AP, Castric V, Kinnison MT, Quinn TP (2004b). The evolution of philopatry and dispersal: homing versus straying in salmonids. In: Hendry AP, Stearns SC (eds). Evolution Illuminated: Salmon and Their Relatives. Oxford University Press: Oxford, pp 52-91. 
Hendry AP, Day T, Taylor EB (2001). Population mixing and the adaptive divergence of quantitative traits in discrete populations: a theoretical framework for empirical tests. Evolution 55: 459-466.

Hendry AP, Kinnison MT (1999). The pace of modern life: measuring rates of contemporary microevolution. Evolution 53: $1637-1653$.

Hendry AP, Wenburg JK, Bentzen P, Volk EC, Quinn TP (2000). Rapid evolution of reproductive isolation in the wild: Evidence from introduced salmon. Science 290: 516-518.

Holtgrieve GW, Schindler DE (2011). Marine-derived nutrients, bioturbation, and ecosystem metabolism: Reconsidering the role of salmon in streams. Ecology (in press).

Hutchings JA (2005). Life history consequences of overexploitation to population recovery in Northwest Atlantic cod (Gadus morhua). Can J Fish Aquat Sci 62: 824-832.

Janetski DJ, Chaloner DT, Tiegs SD, Lamberti GA (2009). Pacific salmon effects on stream ecosystems: a quantitative synthesis. Oecologia 159: 583-595.

Jones CG, Lawton JH, Shachak M (1994). Organisms as ecosystem engineers. Oikos 69: 373-386.

Kendall NW, Hard JJ, Quinn TP (2009). Quantifying six decades of fishery selection for size and age at maturity in sockeye salmon. Evol Appl 2: 523-536.

Kendall NW, Quinn TP (2009). Effects of population-specific variation in age, length, and girth on fishery selection and exploitation rates of sockeye salmon. Can J Fish Aquat Sci 66: 896-908.

Kinnison MT, Hairston Jr NG (2007). Eco-evolutionary conservation biology: contemporary evolution and the dynamics of persistence. Func Ecol 21: 444-454.

Kinnison M, Unwin MJ, Boustead N, Quinn T (1998). Population-specific variation in body dimensions of adult chinook salmon (Oncorhynchus tshawytscha) from New Zealand and their source population, 90 years after introduction. Can J Fish Aquat Sci 55: 554-563.

Kinnison MT, Hendry AP (2001). The pace of modern life II: from rates of contemporary microevolution to pattern and process. Genetica 112: 145-164.

Kinnison MT, Quinn TP, Unwin MJ (2011). Correlated contemporary evolution of life history traits in New Zealand Chinook salmon, Oncorhynchus tshawytscha. Heredity 106: 448-459.

Kinnison MT, Unwin MJ, Quinn TP (2008). Eco-evolutionary vs habitat contributions to invasion in salmon: experimental evaluation in the wild. Mol Ecol 17: 405-414.

Montgomery DR, Buffington JM, Peterson NP, Schuett-Hames D, Quinn TP (1996). Stream-bed scour, egg burial depths, and the influence of salmonid spawning on bed surface mobility and embryo survival. Can J Fish Aquat Sci 53: 1061-1070.

Moore JW, Schindler DE (2008). Biotic disturbance and community dynamics in salmon-bearing streams. J Anim Ecol 77: 275-284.

Moore JW, Schindler DE (2010). Spawning salmon and the phenology of emergence in stream insects. Proc $R$ Soc $B$ 277: 1695-1703.

Moore JW, Schindler DE, Carter JL, Fox JM, Griffiths J, Holtgrieve GW (2007). Biotic control of stream ecosystem fluxes: spawning salmon drive nutrient and matter export. Ecology 88: 1278-1291.

Moore JW, Schindler DE, Scheuerell MD (2004). Disturbance by spawning salmon of Alaskan stream and lake ecosystems. Oecologia 139: 298-308.

Palkovacs EP, Marshall MC, Lamphere BA, Lynch BR, Weese DJ, Fraser DF et al. (2009). Experimental evaluation of evolution and coevolution as agents of ecosystem change in Trinidadian streams. Philos T Roy Soc B 364: 1617-1628.

Pelletier F, Garant D, Hendry AP (2009). Eco-evolutionary dynamics. Philos T Roy Soc B 364: 1483-1489.

Peterson DP, Foote CJ (2000). Disturbance of small-stream habitat by spawning sockeye salmon in Alaska. Trans Am Fish Soc 129: 924-934.
Polis GA, Anderson WB, Holt RD (1997). Toward an integration of landscape and food web ecology: the dynamics of spatially subsidized food webs. Annu Rev Ecol Syst 28: 289-316.

Post DM, Palkovacs EP (2009). Eco-evolutionary feedbacks in community and ecosystem ecology: interactions between the ecological theatre and the evolutionary play. Philos T Roy Soc B 364: 1629-1640.

Post DM, Palkovacs EP, Schielke EG, Dodson SI (2008). Intraspecific phenotypic variation in a predator affects community structure and cascading trophic interactions. Ecology 89: 2019-2032.

Quinn TP (2005). The Behavior and Ecology of Pacific Salmon and Trout. American Fisheries Society: Bethesda, MD.

Quinn TP, Buck GB (2001). Size- and sex-selective mortality of adult sockeye salmon: bears, gulls, and fish out of water. Trans Am Fish Soc 130: 995-1005.

Quinn TP, Carlson SM, Gende SM, Rich HB (2009). Transportation of Pacific salmon carcasses from streams to riparian forests by bears. Can J Zool 87: 195-203.

Quinn TP, Gende SM, Ruggerone GT, Rogers DE (2003). Densitydependent predation by brown bears (Ursus arctos) on sockeye salmon (Oncorhynchus nerka). Can J Fish Aquat Sci 60: 553-562.

Quinn TP, Hendry AP, Buck GB (2001a). Balancing natural and sexual selection in sockeye salmon: interactions between body size, reproductive opportunity and vulnerability to predation by bears. Evol Ecol Res 3: 917-937.

Quinn TP, Kinnison MT (1999). Size-selective and sex-selective predation by brown bears on sockeye salmon. Oecologia 121 273-282.

Quinn TP, Wetzel L, Bishop S, Overberg K, Rogers DE (2001b). Influence of breeding habitat on bear predation and age at maturity and sexual dimorphism of sockeye salmon populations. Can J Zool 79: 1782-1793.

Reznick DN, Ghalambor CK (2001). The population ecology of contemporary adaptations: what empirical studies reveal about the conditions that promote adaptive evolution. Genetica 112: 183-198.

Ruggerone GT, Hanson R, Rogers DE (2000). Selective predation by brown bears (Ursus arctos) foraging on spawning sockeye salmon (Oncorhynchus nerka). Can J Zool 78: 974-981.

Saccheri I, Hanski I (2006). Natural selection and population dynamics. Trends Ecol Evol 21: 341-347.

Schindler DE, Scheuerell MD, Moore JW, Gende SM, Francis TB, Palen WJ (2003). Pacific salmon and the ecology of coastal ecosystems. Front Ecol Environ 1: 31-37.

Seamons TR, Bentzen P, Quinn TP (2007). DNA parentage analysis reveals inter-annual variation in selection: results from 19 consecutive brood years in steelhead trout. Evol Ecol Res 9: 409-431.

Slobodkin LB (1961). Growth and Regulation of Animal Populations. Holt, Rinehart and Winston: New York, NY.

Steen RP, Quinn TP (1999). Egg burial depth by sockeye salmon (Oncorhynchus nerka): implications for survival of embryos and natural selection on female body size. Can J Zool 77: 836-841.

Taylor EB (1991). A review of local adaptation in Salmonidae, with particular reference to Pacific and Atlantic salmon. Aquaculture 98: 185-207.

Waples RS, Jensen DW, McClure M (2010). Eco-evolutionary dynamics: fluctuations in population growth rate reduce effective population size in chinook salmon. Ecology 91: 902-914.

Weese DJ, Schwartz AK, Bentzen P, Hendry AP, Kinnison MT (2011). Eco-evolutionary effects on population recovery following catastrophic disturbance. Evol Appl (in press).

West-Eberhard MJ (2003): Developmental Plasticity and Evolution. Oxford University Press: New York, NY, p 816.

Williams JG, Zabel RW, Waples RS, Hutchings JA, Connor WP (2008). Potential for anthropogenic disturbances to influence evolutionary change in the life history of a threatened salmonid. Evol Appl 1: 271-285.

Willson MF, Halupka KC (1995). Anadromous fish as keystone species in vertebrate communities. Conserv Biol 9: 489-497. 